\title{
INFECTIONS OF THE BULBO-URETHRAL GLANDS OF COWPER
}

By A. H. HARKNESS, M.R.C.S., L.R.C.P., Hon. Medical Officer in Charge of Venereal Department, St. Peter's Hospital for Stone, Consultant in Venereal Diseases, St. Charles' Hospital

THE bulbo-urethral glands in the male were first described by Méry in I684, and in I699 William Cowper wrote a more detailed thesis on the subject. In studying the anatomy I have gleaned most from Hogge (I904) and Lebreton (I903).

Hogge made his observations by serial sections of the pelvis, in different planes, upon the male fœtus at term and just before term, and also on the newly born. $\mathrm{He}$ describes two principal lobes, an upper and outer which he calls the diaphragmatic gland of Cowper and which is the only gland mentioned in our text-books of anatomy, and an accessory lobe which is situated below and internal to the first and which he calls the bulbar gland of Cowper. The diaphragmatic gland of Cowper is situated between the layers of the urogenital diaphragm. The lobules of the bulbar gland of Cowper are more scattered and are situated in the meshes of the spongy tissue of the bulb, close to the median intrabulbar septum, and are therefore superficial to the anterior layer of the urogenital diaphragm. Sometimes the lobes of the two sides are fused to form a median gland. Hogge considers that the bulbar glands are constant, since they were present in every specimen examined, and he stresses their importance in gonococcal peri-urethral inflammations.

Lebreton carried out dissections on I5 cases, in 9 of which both diaphragmatic glands were present. In 4 no left gland was found, and in 2 both glands were absent. In his dissections he did not find the bulbar glands. The observations of Jarjavay, Henle, Gubler, Kolliker and Wassilief demonstrated them in the adult, and Muller and Hackern in the fotus (Hogge, I904).

Both groups of glands have the same histological structure and develop by buds from the portion of the 


\section{BRITISH JOURNAL OF VENEREAL DISEASES}

urogenital sinus which forms the floor of the spongy portion of the urethra.

The excretory ducts of each diaphragmatic gland, two to three in number, converge towards the midline, unite into a common duct which is joined by the ducts of the bulbar gland, and immediately traverses the spongy tissue and enters the submucosa of the floor of the bulb. Each duct is about $3 \mathrm{~cm}$. in length. The left duct is said to open a little further forward than the right, and on urethroscopy I have often observed this fact. The secretory fibres of Cowper's glands are contained in both the hypogastric and pelvic visceral nerves, but not in the pudic. The hypogastric alone controls the secretion of mucin (Barrington, I9I3). The glands are acinous and are lined by a single layer of columnar cells. They have the same structure as the glands of Littré (Leszezynski, I922).

Most of the functions attributed to these glands are unsupported by experimental evidence (Barrington, I9r3). Throughout the sexual act, from the primary erection to the final orgasm, the glands discharge into the urethra an alkaline mucus which, with the secretions from the other urethral glands, lubricates the urethra. This alkaline secretion neutralises the acidity of the few drops of urine remaining in the urethra after micturition, and enables spermatozoa to live for a longer period. After sexual excitement without gratification the mucus appearing at the external urinary meatus is occasionally mistaken for a urethritis.

Camus and Gley (I896 and I899) state that the secretion of Cowper's glands in the hedgehog coagulates the secretion of the vesiculæ seminales. Cowper's glands are controlled by the internal secretion of the testicles, and John Hunter was the first to prove that they failed to develop at puberty in animals castrated when young. Griffiths (I889) demonstrated that they underwent regression after castration in adult life. It must be remembered, however, that in man they gradually diminish in size as age advances. Heller (I932) has proved that the injection of testis hormone prevents castration atrophy. Removal of Cowper's glands in rats and guinea-pigs has no effect on their breeding powers (Barrington, I9I3).

Inflammation of these small glands is a more frequent 


\section{BULBO-URETHRAL GLANDS OF COWPER}

complication of urethral infections than is generally supposed, and I believe the modern conception, that the residual focus of infection in obstinate cases of gleet is usually in the prostate and vesicles, is not correct. In investigating these cases the anterior urethra receives far too little attention.

Seven years ago I made a conservative estimate that the incidence of Cowperitis was 5 per cent. (Choyce's " System of Surgery," I932), but in my complete series I6 per cent. of cases show signs of inflammation of Cowper's glands. Schischow and Smirnow, quoted by Livermore and Schumann (I929), state that this complication occurred in I $2 \cdot 2$ per cent. of 200 cases of gonorrhœa, and that it is one of the commonest causes of gleet. Leszezynski (I922) set out to ascertain whether there was such a condition as chronic Cowperitis, and examined the glands of 44 consecutive bodies in the post-mortem room, and he was astonished to find that only 25 , or 56.8 per cent., had normal Cowper glands, and that in 16 , or 36 per cent., there was evidence of old or recent inflammation, and further, that one subject in five at the time of his death had an uncured Cowperitis.

Cowperitis can occur during the course of a gonococcal or non-gonococcal urethritis, and I have also, on more than one occasion, been able to diagnose the condition during the investigation of patients for sterility where there has been no history of a urethral infection. The glands are rarely infected with the tubercle bacillus, but cases have been reported by Englisch (I885), Tapret, Conillard, Hartmann and Lecène (I903). I have often had the urine examined for tubercle, but the result has always been negative. Sixteen years ago I saw tubercles in the region of the openings of Cowper's ducts in a patient under the care of Ogier Ward, but the investigation of involvement of Cowper's glands was omitted. Cysts of both diaphragmatic and bulbar glands regarded as congenital in origin are seldom diagnosed, and are usually discovered in the post-mortem room. Occasionally they are large and give rise to symptoms of disturbed micturition, and there is a visible tumour. There are also cysts of the ducts and dilatations of the openings of the ducts. They can only be diagnosed by urethroscopy, and will be described more fully in dealing with the diagnosis of chronic Cowperitis. I contend that some at least of 


\section{BRITISH JOURNAL OF VENEREAL DISEASES}

these conditions are inflammatory in origin. In Muschat's case the pathological report suggested that it might have been inflammatory in origin (I929).

Laquiere and Bouchard (I926) describe a case of calculi of Cowper's gland. Uhle and Archer (I935) have recently reported a case of primary adeno-carcinoma of Cowper's gland in which there was a previous history of gonorrhœa. There are other cases of malignant disease of the glands reported in the literature. Olivieri (I932) excised a cyst, the size of a hen's egg, from the left Cowper area and the histological examination suggested an echinococcal cyst of the left diaphragmatic gland of Cowper.

The majority of cases of infections of these glands are found in a venereal diseases practice, but they are not always venereal in origin. In my series I have recorded cases of involvement of both the diaphragmatic and bulbar glands in descending infections from the upper urinary tract. I have also detected a chronic enlargement of the glands in the investigation of sterility when there has been no history of a urinary infection. The infection, in all probability, reaches the glands by direct spread through their ducts, or possibly by lymphatic spread. It usually occurs after the third week in the course of an attack of acute urethritis. The ducts are of very small calibre and soon become obstructed. The infection may be either acute or chronic.

\section{Acute Inflammation of Diaphragmatic and Bulbar GLANDS OF COWPER}

The symptoms of acute Cowperitis are often very similar to those of an acute prostatitis and prostatic abscess, and on several occasions I have had patients sent to me with a diagnosis of acute prostatitis and on examination proved conclusively that the cause of the trouble was an acute inflammation of a Cowper gland. A definite diagnosis can only be made by bi-digital rectal examination. On passing the forefinger into the rectum the thumb. should be placed in the perineum, on either side of the median raphé. In grasping the urogenital diaphragm between the thumb and forefinger it will be found to be enlarged and thickened, and there is usually an inch or more between the thumb and forefinger, but in the early stages it is rarely possible to detect a definite glandular enlargement. The least pressure causes excruciating 


\section{BULBO-URETHRAL GLANDS OF COWPER}

pain. I consider that the swelling is largely due to a peri-Cowperitis, an opinion which has been confirmed by the four chronically infected Cowper glands which I have had excised, as they all showed a peri-Cowperitis. On four occasions only have I been able to find a bilateral enlargement, and in one case there was an infection of a left diaphragmatic gland and a right bulbar gland. There is pain and heaviness in the perineum, and pain on defæcation. On going carefully into the history the patient will often tell you that the pain radiates to the affected side. Owing to the gland's position in the urogenital diaphragm the act of urination is often extremely painful, and four of my patients were admitted with retention of urine. In three of these the diaphragmatic gland was involved, and in one the bulbar gland. In the latter case there was much difficulty in passing even a small catheter to relieve the retention and an erroneous diagnosis of urethral stricture was made. Subsequent investigation, after the acuteness had subsided, proved that there was no stricture and only enlarged Cowper ducts. Retention of urine is partly due to the swelling of the gland and ducts encroaching on the lumen of the membranous urethra, and partly to spasm of the compressor urethræ muscle. When there is an acute infection of the bulbar gland the condition is diagnosed as a peri-urethral abscess, and it is usually only when the acuteness has subsided that one can diagnose the true cause of the swelling.

With appropriate treatment the infection will usually subside and become chronic, but occasionally it will go on to abscess formation. When the infection is subsiding a small hard gland can be palpated, and on more than one occasion in the subacute state there has been a feeling of fluctuation which has given me the impression that the gland was surrounded by fluid. In the subacute stage it is often impossible to palpate a definite enlargement of the gland; there is only a thickening of the urogenital diaphragm, which in time returns to normal.

An abscess of the bulbar gland will appear as a fluctuating tumour in the region of the floor of the bulb, and when seen early will point on the affected side. In two of my cases where there was an abscess of a diaphragmatic gland, the pus tracked down through the lower layer of the triangular ligament, no doubt through the small opening made by the duct, and a small sausage-

v.D. 


\section{BRITISH JOURNAL OF VENEREAL DISEASES}

shaped tumour was palpated in the subcutaneous tissues of the floor of the penile urethra. The proximal end of the swelling was continuous with an acutely tender swelling of one side of the urogenital diaphragm, but the distal end and lateral walls were lying free, and had no connection with the bulbous urethra. On both occasions the swellings resolved without surgical measures.

There were six cases in my series where it was necessary to seek surgical aid for an abscess in the diaphragmatic gland; in all six gonococci were found in cultures and smears from the pus evacuated. Two of the six patients were admitted with a diagnosis of gonorrhœa and ischiorectal abscess, the abscess being considered to have no relation to the urethritis.

Treatment.-The patient should rest in bed and be given Sitz baths night and morning. Anterior and posterior irrigations with a weak and warm solution of potassium permanganate should be carried out twice a day. In all acute urethral inflammations it is unwise to pass instruments, but this is occasionally necessary when palliative measures failed to relieve retention of urine. In these cases the anterior urethra should be irrigated with I/4,000 oxycyanide of mercury, and when it is thoroughly cleansed the pressure should be raised to 3 feet and a posterior irrigation attempted. This procedure is often successful, as it is also in cases of retention due to acute prostatitis, but when it fails a small rubber catheter should be passed. In my experience it has been necessary to drain an abscess on ten occasions, six for involvement of the diaphragmatic gland, and four for the bulbar gland. All the diaphragmatic cases were originally diagnosed as ischio-rectal, perineal, peri-prostatic, or peri-urethral abscess. Livermore and Schumann (I929) state that fistulæ nearly always follow spontaneous rupture of these abscesses. Fistulæ persist because the secretions from the gland pass through them instead of finding their way to the urethra (Lebreton, r903). When fistulæ persist it is necessary to excise the remains of the gland before effecting a cure.

Chronic Inflammation of the Diaphragmatic and Bulbar Glands

In at least 80 per cent. of cases the onset is insidious, and there is no history of an acute infection of the glands. 
In my series this complication was usually discovered whilst investigating a patient who was not reacting to routine treatment after the fifth or sixth week of the primary infection, or whilst carrying out preliminary tests for cure. I saw my first case sixteen years ago when a former house surgeon of St. Peter's Hospital, Llewellyn Davies, palpated a small hard swelling, about the size of a hazel nut, in one of the Cowper areas of a patient who was suffering from a gleet, and we came to the conclusion that it was a chronically inflamed gland of Cowper. It was the type of gland which could be felt by the index finger in the rectum, without the aid of the thumb on the perineum. Since that date it has been my routine in all rectal examinations to palpate the Cowper areas, and I have collected over Ioo cases in which signs of chronic infection were found. If this examination were included in the routine investigations by all venereologists, many cases would be diagnosed and there would not be such a paucity of literature on the subject. The prostate and vesicles would then cease to be the arch-fiends cloaking ignorance in the diagnosis and treatment of chronic gonococcal infections. Chronic infection of the glands is a cause of relapse, and in 5 per cent. of my cases of gonococcal arthritis it has been the cause of this metastatic complication. Pasteau (I906) also stresses the importance of chronic Cowperitis in blood borne infections.

As in acute inflammation of the glands, the bi-digital rectal examination is the most important aid to diagnosis. The urogenital diaphragm is compressed between the thumb and forefinger, first on one side, and then on the other, and both sides are palpated for the bulbar glands, which are always adherent to the corpus spongiosum. The gland varies in size from a small pea to a large hazel nut. It is very hard, and does not feel at all unlike a malignant lymphatic gland. The enlargement is often bilateral. In my series the left gland was enlarged in 29 per cent. of the cases, and the right in 23 per cent., and both glands were palpable in 48 per cent. Unfortunately I had not, until recently, read Hogge's articles on the anatomy of Cowper's glands, and in my notes of the cases I had not differentiated between the two types of glands, although I had occasionally noted that some of the glands were adherent to the bulb. 


\section{BRITISH JOURNAL OF VENEREAL DISEASES}

Air distension urethroscopy is sometimes a useful aid in the diagnosis of chronic Cowperitis. It is not my practice to pass instruments during the acute stages of the disease, so I am unable to give the urethroscopic picture of acute Cowperitis.

In the normal urethra it is possible to see the small openings of the ducts situated a quarter of an inch distal to, and on the floor of the bulb, and about an inch and a quarter from the opening into the membranous urethra. At times the thin ducts are seen and they appear to come from the opening of the membranous urethra. They diverge slightly and then converge (forming an ellipse). The left duct is often seen to open further forward than the right.

Occasionally there is a redness, bogginess, and thickening of the mucous membrane on the floor of the bulb, but the most constant picture is a thickening of Cowper's ducts. (Figs. I, 2, 3.) They are two to three times their normal size, and are easily seen. It is impossible to see the whole of the submucous course of the ducts in one field. In I2 per cent. of my cases I have seen large or small dilatations of the openings of the ducts, some single and some double, which do not look at all unlike false passages. This condition is usually referred to as a congenital dilatation of the openings of Cowper's duct, and although I have seen them in cases where I could detect no abnormality of Cowper's glands, I consider that at least a certain percentage of them are inflammatory in origin, and are due to a gonococcal or non-gonococcal infection of Cowper's ducts and glands, although I must admit that I have never seen pus exuding from them. Perhaps this is because I never carry out a urethroscopy during the acute stage of the disease. On one occasion I was called in consultation by a colleague. The patient, during the treatment for acute gonorrhœa, had had, one month before I saw him, an acute posterior infection with retention of urine accompanied by a high temperature and repeated rigors, and although there had been no enlargement of the prostate he was thought to have a small prostatic abscess. When I first examined him the temperature had subsided and there were no acute symptoms, but there was, on rectal examination, a large, tender swelling in the left Cowper area, and on urethroscopy I saw one of these so-called cystic openings on the 


\section{BULBO-URETHRAL GLANDS OF COWPER}

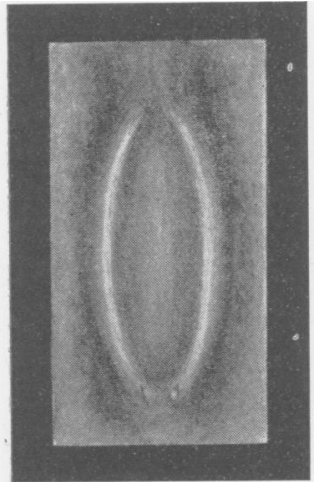

FIG. I.

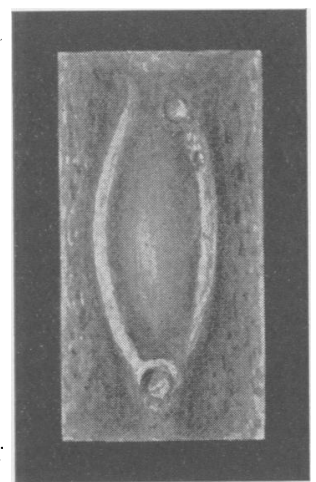

FIG. 2.

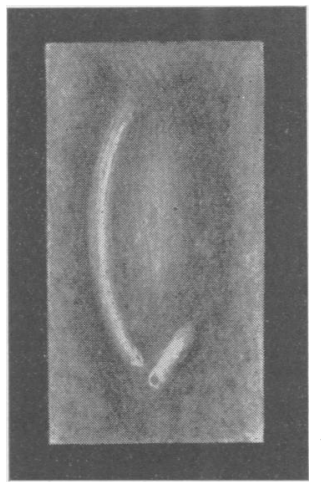

FIG. 3.

FIGS. I, 2, 3.-Thickening of Cowper's ducts in chronic Cowperitis. Three openings into the left duct (Fig. 2). Left duct opening further forward than the right (Fig. 3).

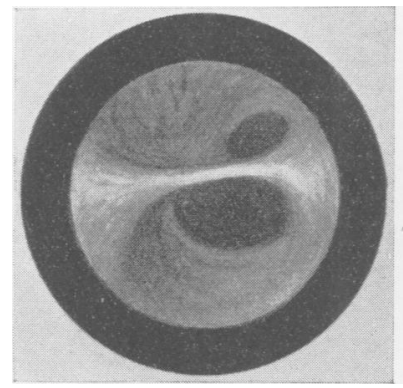

FIG. 4.

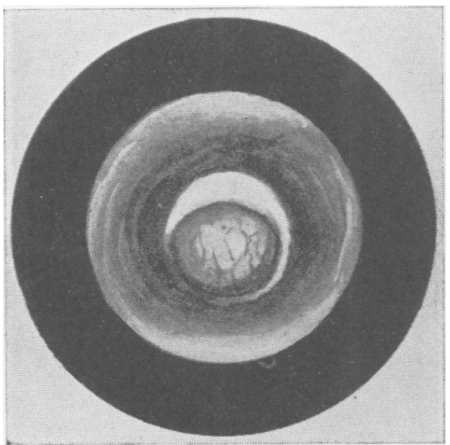

Fig. 6.

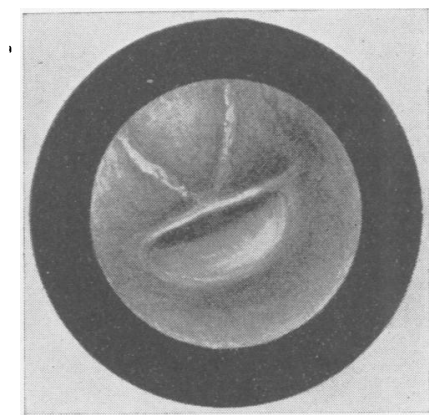

FIG. 5.

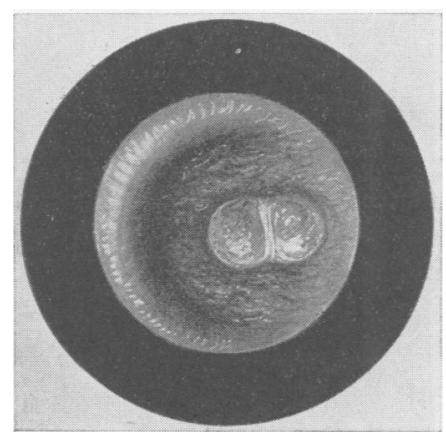

FIG. 7 .

舟

FIGs. 4, 5, 6.-Dilatations of Cowper's ducts situated in the region of the openings of the ducts and usually referred to as being congenital dilatations of the openings of the ducts.

FIG. 7.-Small cyst in the region of the openings of Cowper's ducts. 


\section{BRITISH JOURNAL OF VENEREAL DISEASES}

floor of the bulb. Three weeks later he was passed to me for treatment and the cyst I had previously seen had entirely disappeared. A sound is sometimes caught up in one of these cystic openings, and if urethroscopy has not been carried out a diagnosis of stricture will be made. On three occasions I have seen small openings into the ducts during their submucous course after they have perforated the spongy tissue of the bulb (Fig. 2). They are similar to, but much smaller than, the openings previously described. The lobules of the bulbar glands are often very scattered and thin minute ducts open direct into the main duct on the floor of the bulb. It is possible that these small cavities which are seen with the urethroscope are the results of inflammations at these duct junctions. Once, whilst observing the openings of the ducts in a case of chronic Cowperitis, my assistant carried out a massage of the gland and I observed a thin plug of muco-pus exude from one of the openings. I have seen five patients with small mucous cysts on the floor of the bulb (Fig. 7), and in two of these I could palpate the diaphragmatic gland of Cowper.

Treatment.-Whether the duct of the gland is open or occluded, the best treatment is to continue with urethrovesical irrigations, and to carry out massage of the gland twice a week. In all cases which have definitely followed an acute infection of the glands, it is essential to omit massage until the acuteness of the infection is subsiding.

Intra-urethral treatment with the aid of the urethroscope is not considered practicable.

Several workers have advocated excision of all glands that are palpable. I do not consider that this procedure is necessary. In my series only two patients were passed to a surgical colleague at St. Peter's Hospital for excision of a palpable gland, and in both there was no residuary urinary infection and the operations were performed for perineal pain.

In I903 at St. Peter's Hospital, Swinford Edwards excised a left Cowper gland for perineal pain, and when the operation was performed there was no urinary infection, but, as in my cases, there was a previous history of gonorrhœa. One other patient, who was suffering from a chronic infection of the left gland with a patent duct, and had had two relapses, was also transferred to the surgeon. After omitting treatment, and 


\section{BULBO-URETHRAL GLANDS OF COWPER}

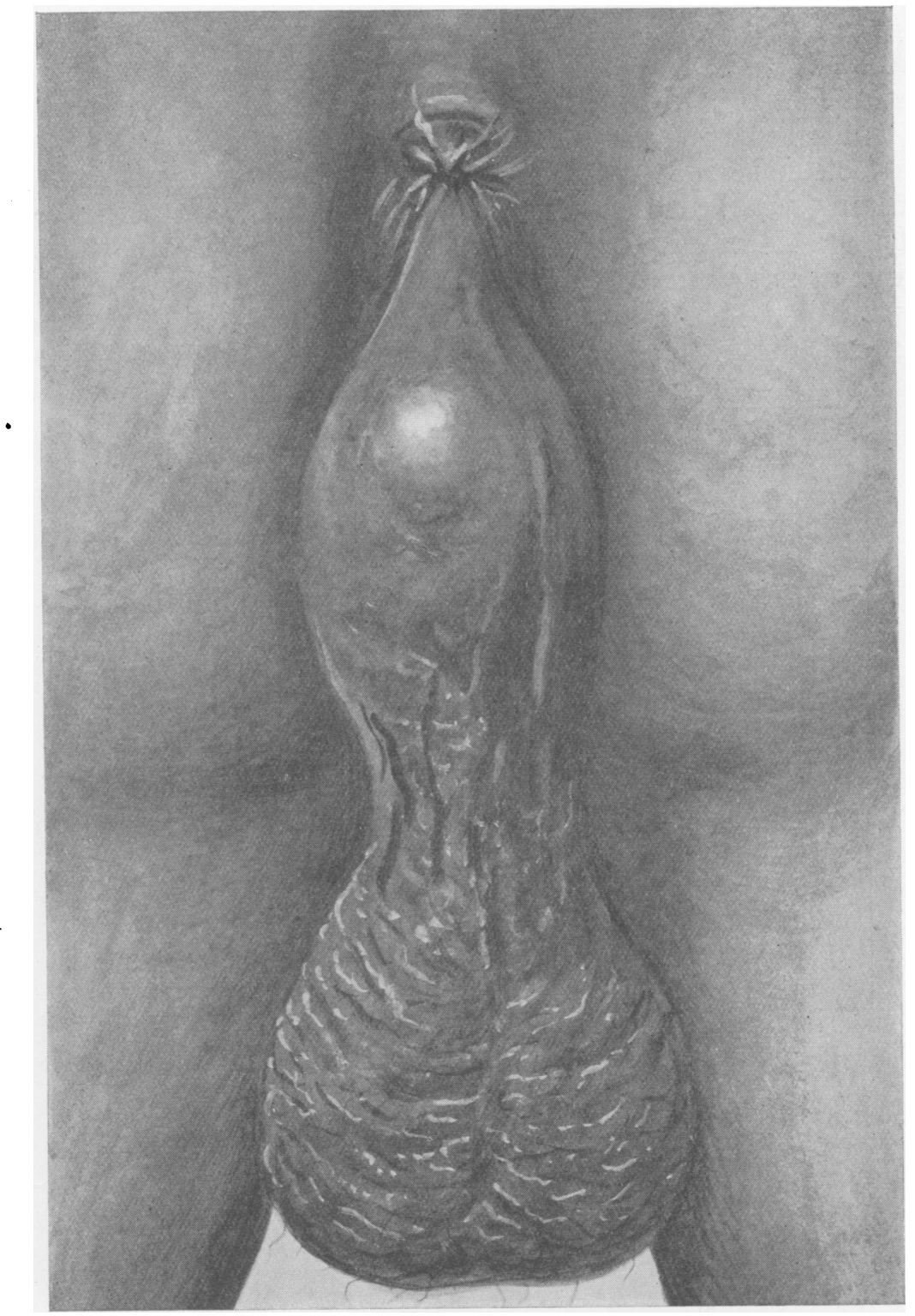

FIG. 8.-Abscess of left diaphragmatic gland of Cowper pointing on left side of perineum.

permitting the patient to take alcohol, the infected products of the gland reinfected the urethra. Unfortunately the patient had to leave England just before the operation, and the opportunity to excise and examine histologically 


\section{BRITISH JOURNAL OF VENEREAL DISEASES}

an infected gland, which was known to harbour gonococci, was lost. All my other patients have reacted to massage of the gland and urethral irrigations, and I have not felt justified in advising operation. Even when the urethral infection is cured, a large percentage of patients (more than $5^{\circ}$ per cent.), still have glands which are palpable. I have followed several cases for as long as fifteen years, and although the gland has still been palpable, and the urethroscopic picture has remained unaltered, the urine is still clear with no threads and the Complement Fixa-

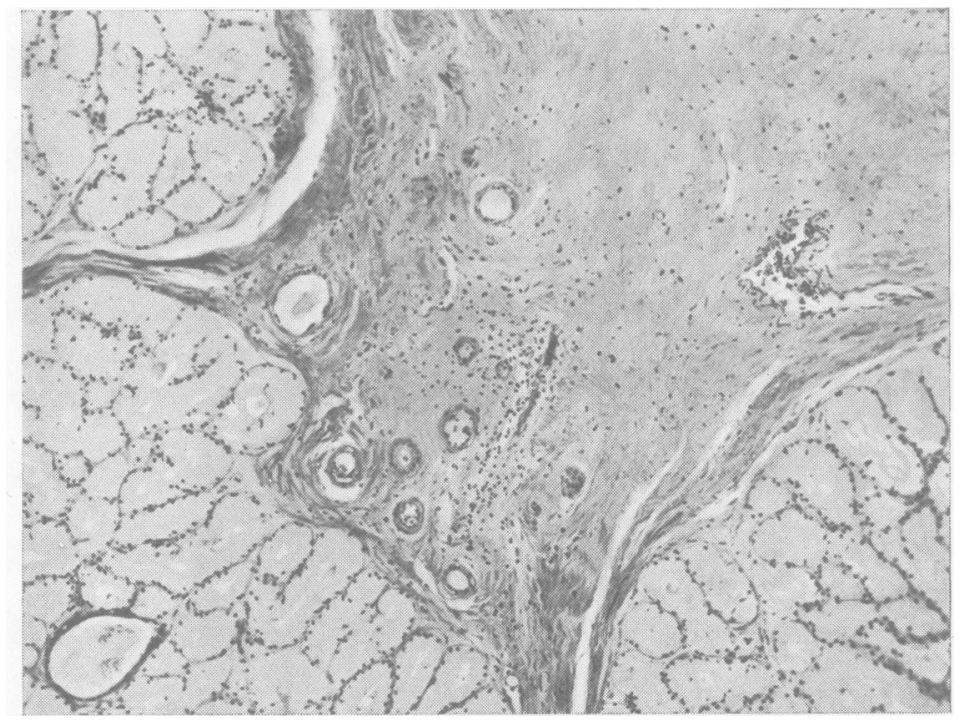

FIG. 9.-Section of a Cowper gland, showing peri-Cowperitis, which was excised for perineal pain $\times 80$.

tion Test is still negative. In the two cases where the glands were excised sections showed a well-marked periCowperitis, but the glandular epithelium appeared to be normal (Fig. 9).

\section{Selected Cases showing the Importance of Latent Inflam- mation of Cowper's Glands as a Cause of Relapse}

Case 1.-Age 23. Previous history showed that the patient had contracted gonorrhœa, I4/5/23, and was discharged as cured, 29/9/23. Since that date he had not laid himself open to re-infection. First consulted me three weeks later for a slight urethral discharge and pains 
in the perineum. A smear of the urethral discharge contained gonococci. Posterior irrigations with potassium permanganate $\mathrm{I} / 6,000$ were prescribed, and in two days there was no discharge and the urine was clear with a few threads in the first glass. Urethroscopy showed a few small areas of soft infiltration, 2 inches from the meatus, but nothing abnormal was seen on the floor of the bulb. The prostate and the vesiculæ seminales were normal. The left diaphragmatic gland of Cowper was about the size of a hazel nut, and on palpation was definitely tender. After a two-months' course of massage and irrigations it was impossible to palpate the gland, and the urine was clear with no threads.

Case 2.-Age 33. Consulted me in December, I930. Previous to seeing me he had been in a nursing-home for eight weeks and had had a course of prostatic massage and irrigations for " non-specific prostatitis with a toxic dermatitis." There was a previous history of gonorrhœa, eighteen months before seeing me, and in the early stages of the infection he had developed a left epididymitis. On examination the rash was definitely scabetic. There was no urethral discharge and the urine was clear with a few threads in the first glass. Anterior urethroscopy showed enlarged ducts of Cowper. Smears after prostatic and vesicular massage were negative. There was marked thickening and tenderness of the left urogenital diaphragm, but I was unable to detect a definite glandular swelling. On the morning following this examination there was a profuse urethral discharge containing large numbers of gonococci. Posterior irrigations were given, the left Cowper area was massaged twice a week, and in a month it had returned to normal. After carrying out the usual tests the patient was discharged as cured. I had the opportunity to make a further examination three years later; the urine was still clear, with no threads, and I could detect no abnormality in the left Cowper area.

Case 3.-Age 2I. Attended me for acute gonorrhœa, 26/2/23. Was very irregular in his attendances, and six weeks later, when on holiday, he developed pain on the left side of the perineum, the pain being more severe during defæcation and micturition. There was a feeling that the anus was distended with fæces. He remained in bed for ten days, and I made an examination three weeks later and found the left Cowper gland enlarged and 


\section{BRITISH JOURNAL OF VENEREAL DISEASES}

tender. After a month's course of massage the urine cleared, the gland became much smaller in size and was not tender, but even when the patient was discharged as cured, six months later, the gland was still just palpable.

\section{Acute Infection of Left Diaphragmatic Gland with Perineal Abscess}

Case 4.-Age 23. During the fourth week of an attack of acute gonorrhœea the patient developed pains in the rectum and perineum. The temperature rose to $100 \cdot 6^{\circ}$ and there were urinary symptoms which suggested an acute posterior urethritis. On rectal examination the prostate, vesicles and the right Cowper region felt normal. The left urogenital diaphragm, however, was three times its normal size and acutely tender. Irrigations were continued and Sitz baths and atropine and morphia suppositories prescribed. Ten days later an abscess pointed on the left side of the perineum (Fig. 8). This was opened and drained and smears of the pus evacuated showed gonococci; cultures also yielded a growth of gonococci. The wound healed in three weeks and the patient, who is still under my care, is continuing with massage of the left urogenital diaphragm. There is still slight thickening, but the gland is not palpable. Urethroscopy shows that the left duct of Cowper is three times its normal size and the right duct is only slightly enlarged.

\section{Acute Infection of Right and Left Diaphragmatic Glands with Peri-anal Abscess}

Case 5.-Age I7. Contracted gonorrhœa four weeks before seeing me, and gave a fortnight's history of pain in the perineum. Rectal examination showed marked tenderness and swelling of the right and left urogenital diaphragm. A peri-anal abscess developed and was drained. Smears and cultures of the pus evacuated were positive for gonococci. All tests were negative for rectal gonorrhœa. Posterior irrigations were prescribed and in fourteen days this was augmented by massage of both Cowper areas twice a week. A month has elapsed and the patient is still under my care. The urine is clear with no threads and there is a small blind external fistula still harbouring gonococci. There is now only slight thickening of the right and left urogenital diaphragm. 


\section{BULBO-URETHRAL GLANDS OF COWPER}

\section{Acute Infection of Right Diaphragmatic Gland with Ischio-rectal Abscess}

Case 6.-Age 27. Admitted 24/9/35, with a profuse gonococcal urethral discharge and a right-sided ischiorectal abscess which had been incised a few days before admission. The history of the present illness showed that he contracted gonorrhœa three months previously. On examination there was a large right-sided ischio-rectal abscess which was discharging freely. Smears and cultures of the pus from the abscess were positive for gonococci, and on rectal examination there was marked thickening and tenderness of the right urogenital diaphragm. There was also a urethral discharge containing gonococci. Prostate and vesicles were normal. C.F.T., strongly positive. Wassermann and Kahn, negative. Cowper massage twice a week, posterior irrigations and Sitz baths were prescribed. The ischio-rectal abscess was syringed with eusol. Patient remained under observation for a month. The abscess had almost healed and urine was clear with a few small threads in the first glass only. When last seen a hard right diaphragmatic gland of Cowper, about the size of a pea, was definitely palpable.

\section{Right Diaphragmatic and Left Bulbar Gland excised for Perineal Pain Associated with Coitus}

Case 7.-Age 44. First attended me in August, I923. There was a previous history of syphilis in I905, and gonorrhœa in I908 and I909. He was discharged as cured in I9Io.

For two years he had experienced pain after coitus. The pain lasted for several days and radiated from the anus to the buttocks, but was not affected by defæcation. During the last few months the pain was more severe and more or less continuous. He had visited several clinics and was diagnosed as a post-gonococcal neurosis.

On examination there was no urethral discharge and the urine was clear with no threads. A bidigital rectal examination revealed an enlarged and tender right diaphragmatic and left bulbar gland. The prostate and vesicles felt normal, and smears after massage were negative for pus cells and organisms. Urethroscopy and cystoscopy were also negative.

Massage for three months failed to relieve the pain, 


\section{BRITISH JOURNAL OF VENEREAL DISEASES}

and the patient was admitted under Sir John Thomson Walker, who excised the glands. The bulbar gland was embedded in the substance of the corpus spongiosum, and there was a good deal of bleeding. The operation was completely successful, and when the patient was seen two years later he had remained free from symptoms.

\section{SUMMARY}

Some aspects of the structure and functions of the bulbo-urethral glands of Cowper are discussed in relation to common inflammatory diseases of these glands. Attention is drawn to the importance of the "bulbar gland " of Cowper which is distinct from the diaphragmatic portion to which the descriptions of most text-books are limited. In the author's series evidence of acute or chronic infection of Cowper's glands was found in I6 per cent. of his cases. Acute infections were almost always unilateral, but in the series with chronic involvement the left gland was affected in 29 per cent. ; the right in 23 per cent., and both glands were palpable in 48 per cent. The symptoms, signs and differential diagnosis of these infections are discussed and the author's methods of treatment described. The importance of Cowperitis as a cause of relapses and metastatic complications of urethritis and as a source of errors in diagnosis is emphasised. Seven selected cases from the author's series are described.

\section{ConCLUSIONS}

-(I) The bulbar gland of Cowper is distinct from the diaphragmatic gland, is seldom described in text-books, and is of considerable importance in relation to periurethral infections secondary to urethritis.

(2) One or both portions of the gland are frequently infected in patients with urethritis due to gonococcal and other infections. In this series 16 per cent. of patients showed some evidence of this complication.

(3) Infections of Cowper's glands are seldom diagnosed and the general impression is that they are uncommon. The correct methods necessary to establish the diagnosis are not generally known or are seldom applied. Careful bidigital palpation in Cowper's area, combined with urethroscopic examination of the ducts, should be routine 


\section{BULBO-URETHRAL GLANDS OF COWPER}

in all patients under treatment in the subsiding stage of urethritis or undergoing investigation in the chronic stage.

(4) The possible relationship between urethritis with acute Cowperitis and acute abscesses in the neighbourhood of the anus and rectum should be remembered.

(5) Persistent " gleet " and relapse after presumed cure of urethritis are frequently due to undiagnosed chronic infection of Cowper's glands. Metastatic infection may result from the same focus. For these conditions the prostate and seminal vesicles are often wrongly blamed.

\section{BIBLIOGRAPHY}

Barrington, F. J. F. (I9I3): "The Variations in the Mucin Content of the Bulbo Urethral Glands," Sonderabdruck aus der Internationalen Monatsschrift für Anatomie und Physiologie, Band 30.

Camus, L., and Gley, E. (I896 and I899) : C. R. Soc. Biol.

Choyce, C. C. (1932): "Venereal Diseases other than Syphilis," 1.

CowPER, W. (I698) : "The Anatomy of the Humane Bodies."

Crouse, H. (I9II, September I8th): " Retention Cysts of Cowper Ducts," Bull. El Paso County Med. Ass.

Edwards, S. (I903) : "Excision of Cowper's Gland," Med. Press \& Circ. Lond., n.s., 75, 573.

ENGLISCH (I885): "Anatomie und Pathologie der Cowperschen Drusen," Wien. Med. Presse, 26, I643.

GRIFFITHS (I889): J. Anat. Lond., 24.

HaRTMANN, H., and LecÈne, P. (I903) : " La tuberculose de la glande de Cowper," Ass. franç. d'urol., 6, 237-246.

Heller, R. E. (I932): "Cowper's Gland and its Reaction to Castration and to Different Sex-hormone Conditions," Amer. J. Anat., 48, 26-28.

HoGge, A. (1904) : Ann. Mal. Org. Genito-urinaires, 22, II85-I200.

LAQUIERE, M., and BouchaRD, R. (I926) : "Cowpérite calculeuse," J. d'Urol., 22, 47-48.

LEBRETON, P. (I903-I904): Contribution à l'étude des glandes bulbouréthrales et leur maladies, Thèse de Paris, 239.

LESZCZYNSKI, R. (I922): "Sur la Cowpérite chronique latente." Ann. Mal. vénér., 17, 416-434.

Livermore, G. R., and Schumann, E. A. (I929) : " Gonorrhœa and Kindred Affections," New York and London, 66-69.

Muschat, M. (I929): "Urethral and Perineal Cysts of the Glands of Cowper," J. Urol., 22, No. 2.

OlIVIERI, G. (I932) : "Cisti da echinococco della ghiandola di Cowper," Riforma med., 48, 26-28.

Pasteau, O. (I906): "Les Cowpérites dans l'urétrite chronique," $C$. R. de l'ass. franç. d'urol., 10, 267.

Uhle, C. A. W., and Archer, G. F. (r935) : "Primary Carcinoma of Cowper's Gland ": Report of Case with review of literature. $J$. Urol., 34, I28-I33.

The illustrations have been reproduced for the author from coloured drawings by Mr. S. A. Sewell. 